\title{
Nano-structure study of $\mathrm{ZnO}$ thin films on sapphire grown with different temperature conditions
}

\author{
Shu-Cheng Chin ${ }^{\mathrm{a}}$, Chun-Yung Chi ${ }^{\mathrm{a}}$, Yen-Cheng Lu ${ }^{\mathrm{a}}$, Lin Hong ${ }^{\mathrm{a}}$, Yu-Li Lin ${ }^{\mathrm{a}}$, Fang-Yi Jen ${ }^{\mathrm{a}}$, \\ C.C. Yang ${ }^{\mathrm{a}, *}$, Bao-Ping Zhang ${ }^{\mathrm{b}}$, Yusaburo Segawa ${ }^{\mathrm{b}}$, Kung-Jen $\mathrm{Ma}^{\mathrm{c}}$, Jer-Ren Yang ${ }^{\mathrm{d}}$ \\ ${ }^{a}$ Graduate Institute of Electro-Optical Engineering and Department of Electrical Engineering, National Taiwan University, 1, Roosevelt Road, Sec. 4, Taipei, \\ Taiwan, ROC \\ ${ }^{\mathrm{b}}$ Photodynamics Research Center, RIKEN (the Institute of Physical and Chemical Research), Sendai, Japan \\ ${ }^{\mathrm{c}}$ Department of Mechanical Engineering, Chung Hua University, Hsinchu, Taiwan, ROC \\ ${ }^{\mathrm{d}}$ Department of Material Science and Engineering, National Taiwan University, Taipei, Taiwan, ROC
}

Received 29 July 2005; received in revised form 26 April 2006; accepted 12 May 2006

Communicated by G.B. Stringfellow

Available online 11 July 2006

\begin{abstract}
We compared the nano-structures of three samples of $\mathrm{ZnO}$ thin film on sapphire under different growth temperature conditions. Although disconnected domain structures (on the scale of $100 \mathrm{~nm}$ in size) were observed in the samples of high-temperature (450 ${ }^{\circ} \mathrm{C}$ ) growth, their crystal quality is generally better than the one grown at a low temperature $\left(200^{\circ} \mathrm{C}\right)$, either near or away from the sapphire interface. Lattice misfits and threading dislocations were observed within a domain with the separation of around $8 \mathrm{~nm}$. The sample grown at the low temperature showed a continuous structure through the $\mathrm{ZnO}$ layer although void-like structures might exist inside. However, its crystal quality is relatively poorer. Of the two samples with high-temperature growth, the one with initial low-temperature growth had a larger domain structure (around $150 \mathrm{~nm}$ in size) and relatively lower crystal quality. In particular, strong strains existed near the interface of this sample. The samples of high-temperature growth generally have higher photon emission efficiencies. Temperature-dependent integrated photoluminescence intensities of the high-temperature-growth samples show that the exciton trapping by either intrinsic donors or acceptors leads to a higher thermal quenching rate in comparison with free excitons.
\end{abstract}

(C) 2006 Elsevier B.V. All rights reserved.

PACS: 68.37.Lp; 61.46. +w; 68.55.Jk

Keywords: A1. Exciton; A1. Growth temperature; A1. Nanostructure; A1. Photon emission efficiency; A1. Transmission electron microscopy; B1. ZnO

\section{Introduction}

Because of its large exciton binding energy at about $60 \mathrm{meV}, \mathrm{ZnO}$ has attracted much attention in crystal growth and optical property studies. With such a large exciton binding energy, the dominance of exciton recombination in the radiative process, even up to the room temperature, results in the high photon emission efficiency for device application. Recently, significant progresses in $\mathrm{ZnO}$ crystal quality have been made. Besides the nano-

\footnotetext{
*Corresponding author. Tel.: + 886223657624 ; fax: + 886223652637.

E-mail address: ccy@cc.ee.ntu.edu.tw (C.C. Yang).
}

structures like nano-tubes [1], nano-rods [2], and nanowalls [3], high-quality $\mathrm{ZnO}$ thin films have been grown with molecule-beam epitaxy [4,5], metal-organic chemical vapor deposition (MOCVD) [6,7], and sputtering [8].

In $\mathrm{ZnO}$, because of the existence of $\mathrm{Zn}$ interstitials and $\mathrm{O}$ vacancies, and the substitution of $\mathrm{O}$ by $\mathrm{Zn}$, effective shallow donors are usually formed [9]. A donor can trap an electron to form a neutral donor. A neutral donor can trap a free exciton (FX) to form a donor-bound exciton $\left(\mathrm{D}^{0} \mathrm{X}\right)$. Also, because of the existence of $\mathrm{O}$ interstitials and $\mathrm{Zn}$ vacancies, effective deep acceptors can be formed [10]. A neutral acceptor, which is generated after an acceptor receives a hole, can trap a FX to form an acceptor-bound 
exciton $\left(\mathrm{A}^{0} \mathrm{X}\right)$. Normally, the donor density is higher than the acceptor density in a high-quality $\mathrm{ZnO}$ sample. Another widely observed emission feature in $\mathrm{ZnO}$ is the donor-acceptor pair (DAP) [11]. This emission feature is due to the combination of an electron trapped by a donor and a hole trapped by an acceptor. Because the donor level is quite shallow from the conduction band edge, the DAP transition level can be easily thermalized into the conduction band-neutral acceptor transition level (symbolized by $\mathrm{eA}^{0}$ ) as temperature increases [12]. At medium temperatures, the DAP emission feature coincides with the emission feature of one-LO-phonon-assisted emission, which is about $70 \mathrm{meV}$ (LO phonon energy) below the FX level [13].

The nanostructures of $\mathrm{ZnO}$ heavily rely on the MOCVD growth conditions, particularly on the growth temperature and pressure [6,8,14-17]. By decreasing the growth pressure, the $\mathrm{ZnO}$ nanostructures change from nano-rods into nano-tubes and then nano-walls. $\mathrm{ZnO}$ nano-rods, nano-tubes, and nano-walls are normally obtained at $10-6$, $1-0.3$, and $0.1-0.06$ Torr, respectively, in growth pressure $[16,17]$. In the growth temperature dependence, when the growth temperature is lower than $250^{\circ} \mathrm{C}$, smooth surfaces without grain formation were observed [15]. The migration of atoms on the substrate surface is suppressed at low growth temperatures. However, when the growth temperature is higher, zinc atoms become more diffusive on the substrate surface. They can select sites having smaller lattice mismatch. When the growth temperature is higher than $300{ }^{\circ} \mathrm{C}$ in growing $\mathrm{ZnO}$ on sapphire, we can normally observe that the unit cell of $\mathrm{ZnO}$ is twisted in the $c$-plane by $30^{\circ}$ with respect to that of sapphire $\left(\mathrm{Al}_{2} \mathrm{O}_{3}\right)$ [15]. In this situation, high-quality growth can be achieved with a lower density of misfit dislocation.

In this paper, we use the technique of high-resolution transmission electron microscopy (HRTEM) for studying the nanostructures of three $\mathrm{ZnO}$ thin-film samples, grown on sapphire, of different growth temperature conditions. It is found that generally the crystalline quality is higher in the sample grown at the high temperature through the whole growth procedure. The basic optical measurements show that higher photon emission efficiency can also be obtained with the high growth temperature. This paper is organized as follows: In Section 2, we describe the sample growth conditions and the HRTEM operation conditions. The surface morphologies of the samples are also discussed here. Then, in Section 3, we present and discuss the images of HRTEM of these samples. The results of basic optical characterization are shown in Section 4. Finally, conclusions are drawn in Section 5.

\section{Sample preparation and research approaches}

All the three $\mathrm{ZnO}$ thin-film samples were grown with MOCVD on (0001) sapphire substrate with 6Torr in pressure. Sample A was grown at $450{ }^{\circ} \mathrm{C}$ for $90 \mathrm{~min}$. In this sample, measurements by using X-ray diffraction (XRD) revealed that the in-plane orientation of $\mathrm{ZnO}$ unit cell is $30^{\circ}$ twisted relative to that of the sapphire substrate [15]. Sample B was grown at $200{ }^{\circ} \mathrm{C}$ for $90 \mathrm{~min}$. In this sample, the in-plane orientation of $\mathrm{ZnO}$ unit cell is not twisted. Sample C was grown at $200{ }^{\circ} \mathrm{C}$ for $5 \mathrm{~min}$ first, followed by 90-min growth at $450^{\circ} \mathrm{C}$. In this situation, the in-plane orientation of $\mathrm{ZnO}$ unit cell is not twisted either. The HRTEM investigations were performed using a Philips Tecnai F30 field-emission electron microscope using an acceleration voltage of $300 \mathrm{kV}$ and a probe forming lens of $\mathrm{Cs}=1.2 \mathrm{~mm}$. The current density focused onto the samples was estimated to be lower than $16 \mathrm{~A} / \mathrm{cm}^{2}$.

Figs. 1-3 show scanning electron microscopy (SEM) images of samples A-C, respectively. In Fig. 1 for sample $\mathrm{A}$, which was grown at the high temperature, spiral domain

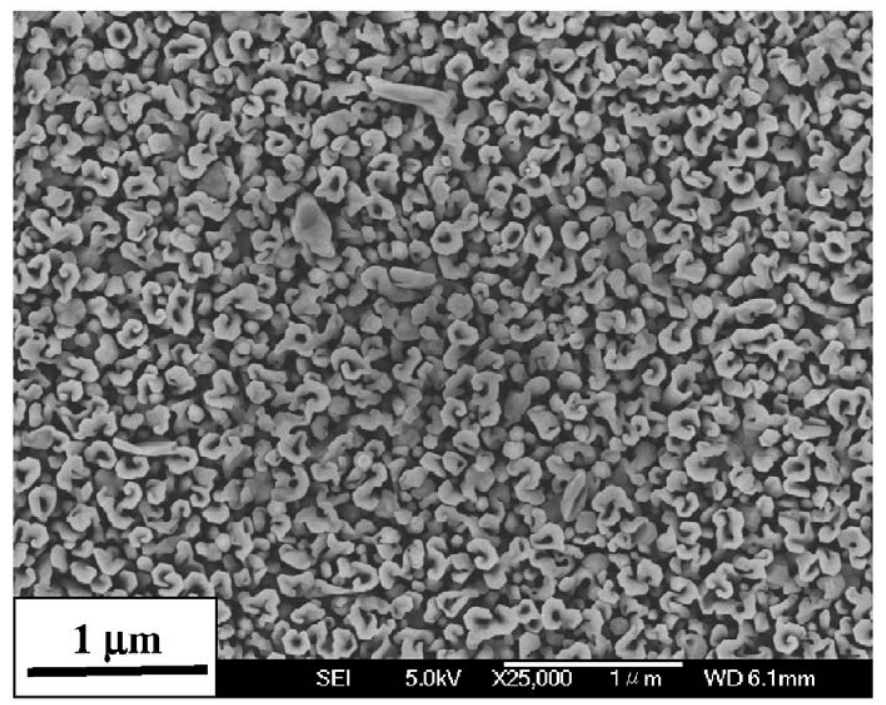

Fig. 1. An SEM image of sample A.

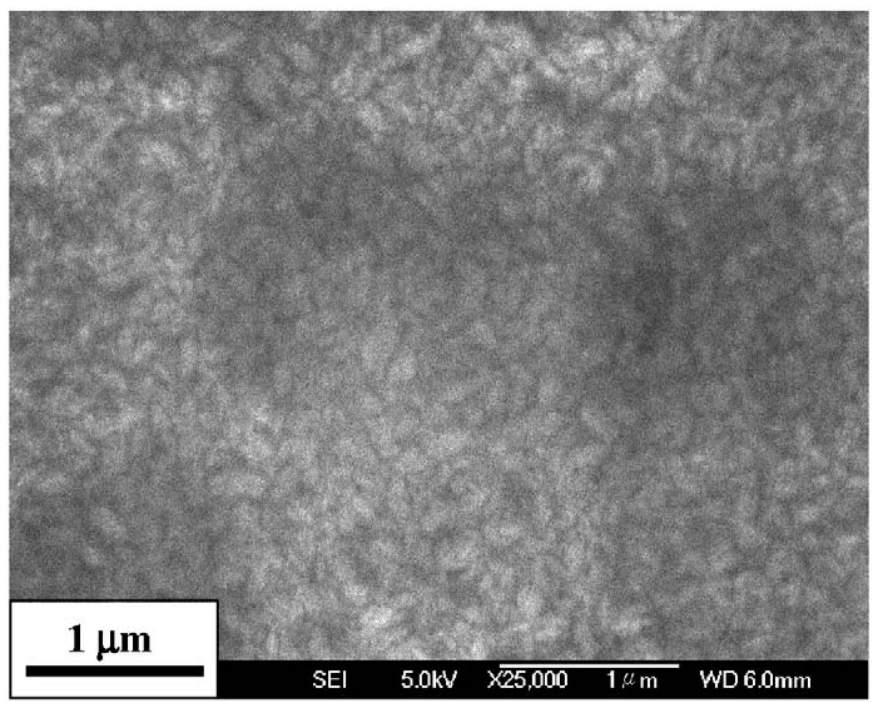

Fig. 2. An SEM image of sample B. 


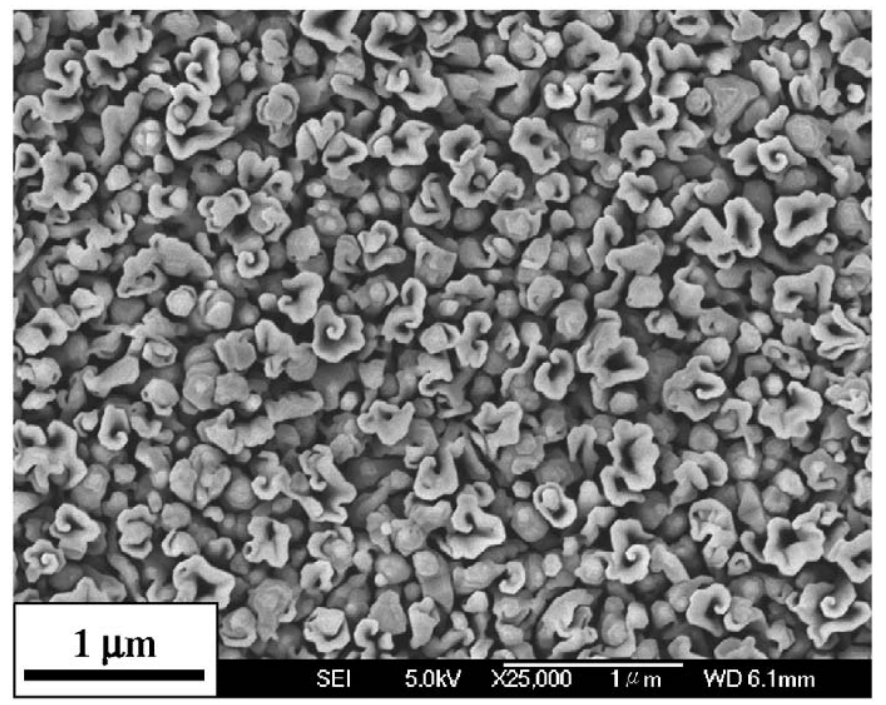

Fig. 3. An SEM image of sample C.

structures with a scale size of $100 \mathrm{~nm}$ can be seen. The $\mathrm{ZnO}$ thin film is actually composed of random domain structures and air gaps. The surface morphology looks like a mixture of flowers in full blossom and flower buds. However, in Fig. 2 for sample B, which was grown at the low temperature, although domain structures can be seen, they seem to be well connected. Then, in Fig. 3 for sample $\mathrm{C}$, which was initially grown at the low temperature, followed by the high-temperature growth, spiral domain structures similar to those in sample A (a mixture of flowers in full blossom and flower buds) can be observed. Nevertheless, the domain structures are larger in scale size (around $150 \mathrm{~nm}$ ), when compared with sample A.

\section{Images of transmission electron microscopy (TEM)}

Fig. 4 shows a large-scale TEM image of sample A. Here, one can clearly see that the thin film actually consists of separate domain structures that are consistent with the surface morphology shown in Fig. 1. The cross section of a domain is around $100 \mathrm{~nm}$ in size. The domains seem to be mutually separated starting from the $\mathrm{ZnO} /$ sapphire interface. Fig. 5 shows an HRTEM image around the $\mathrm{ZnO} /$ sapphire interface of sample A. The interface is quite clear. Generally speaking, the $\mathrm{ZnO}$ crystalline quality is high. It is noted that although atomic point image can be seen in the sapphire layer, only line structures are seen in the $\mathrm{ZnO}$ layer. This difference indicates the different crystal orientations between the two layers, confirming that the $\mathrm{ZnO}$ basal plane is twisted by $30^{\circ}$. Fig. 6 shows a typical HRTEM image in the shallow layer of $\mathrm{ZnO}$. Here, two threading dislocations along the $c$-axis with the separation of about $8 \mathrm{~nm}$ can be clearly seen. Except the threading dislocations, the crystalline quality of $\mathrm{ZnO}$ is actually quite good. Because of the large lattice mismatch between sapphire and $\mathrm{ZnO}$, threading dislocations can be found along the interface. Such a structure can be seen in Fig. 7.

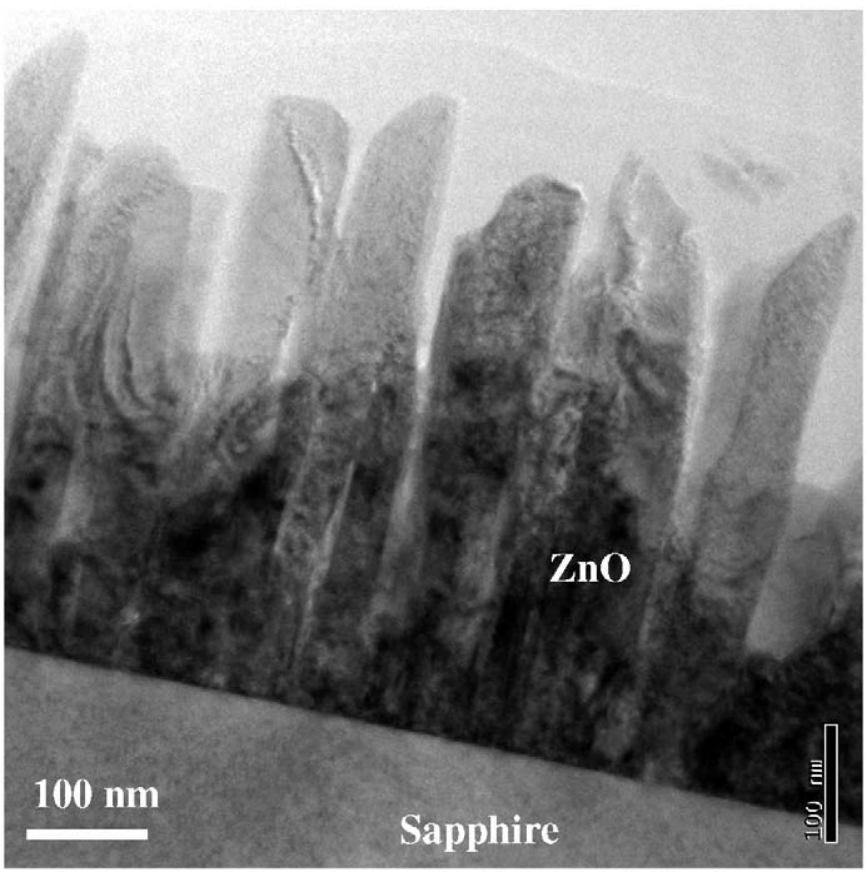

Fig. 4. A large-scale TEM image of sample A showing the domain structures. The domain size is around $100 \mathrm{~nm}$.

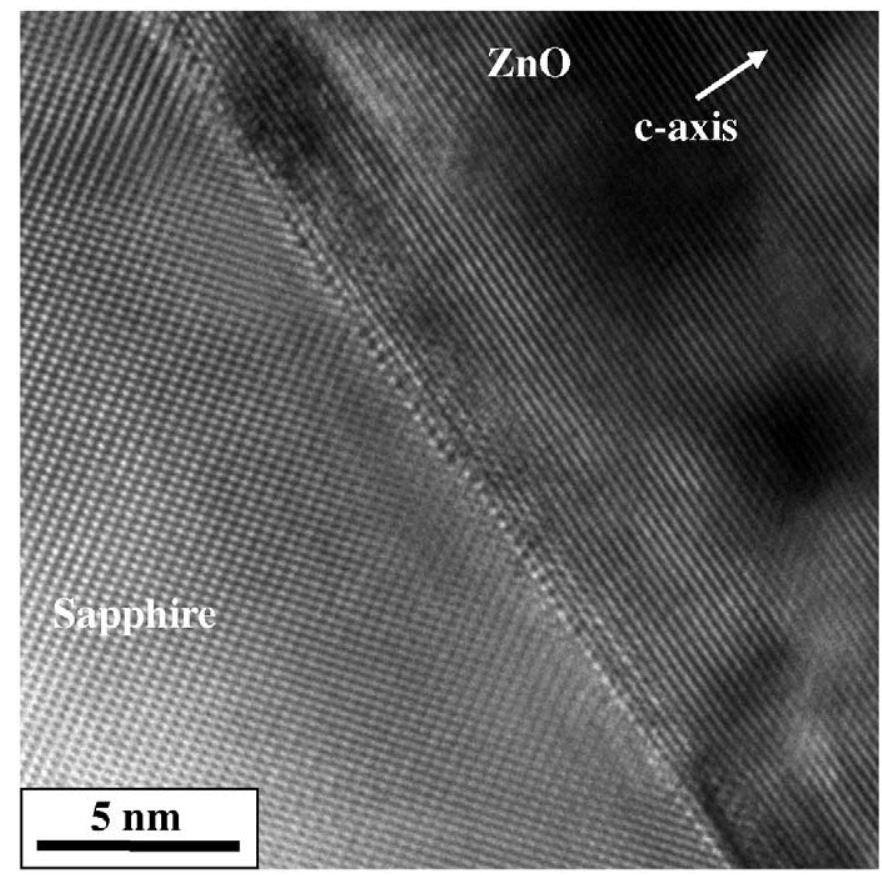

Fig. 5. A TEM image showing the interface between the sapphire substrate and $\mathrm{ZnO}$ of sample $\mathrm{A}$.

As indicated with arrows, three threading dislocations can be seen in this HRTEM image. The separation between two neighboring dislocations is about $8 \mathrm{~nm}$. A misfit dislocation exists in this range for releasing the built strain. Such a threading dislocation extends along the $\mathrm{ZnO}$ growth in the $c$-axis. It is noted that the $30^{\circ}$ twist of the $\mathrm{ZnO}$ basal plane, relative to the sapphire crystalline, has reduced the 


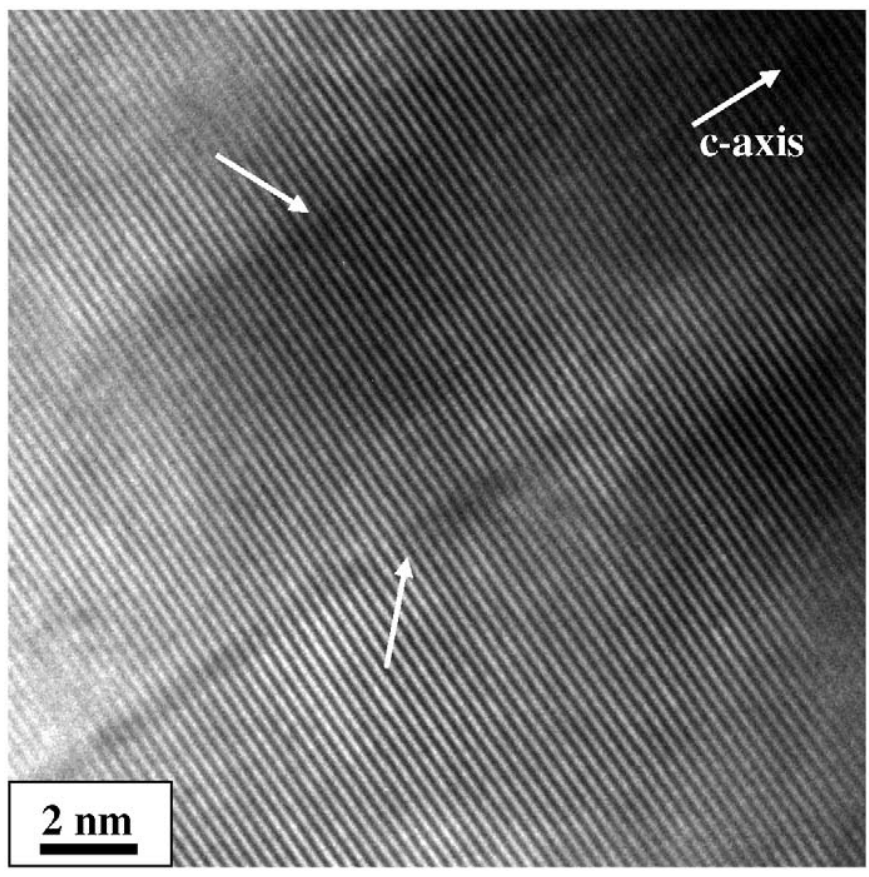

Fig. 6. A TEM image showing the $\mathrm{ZnO}$ structure of sample A. Two threading dislocations separated by about $8 \mathrm{~nm}$ can be seen.

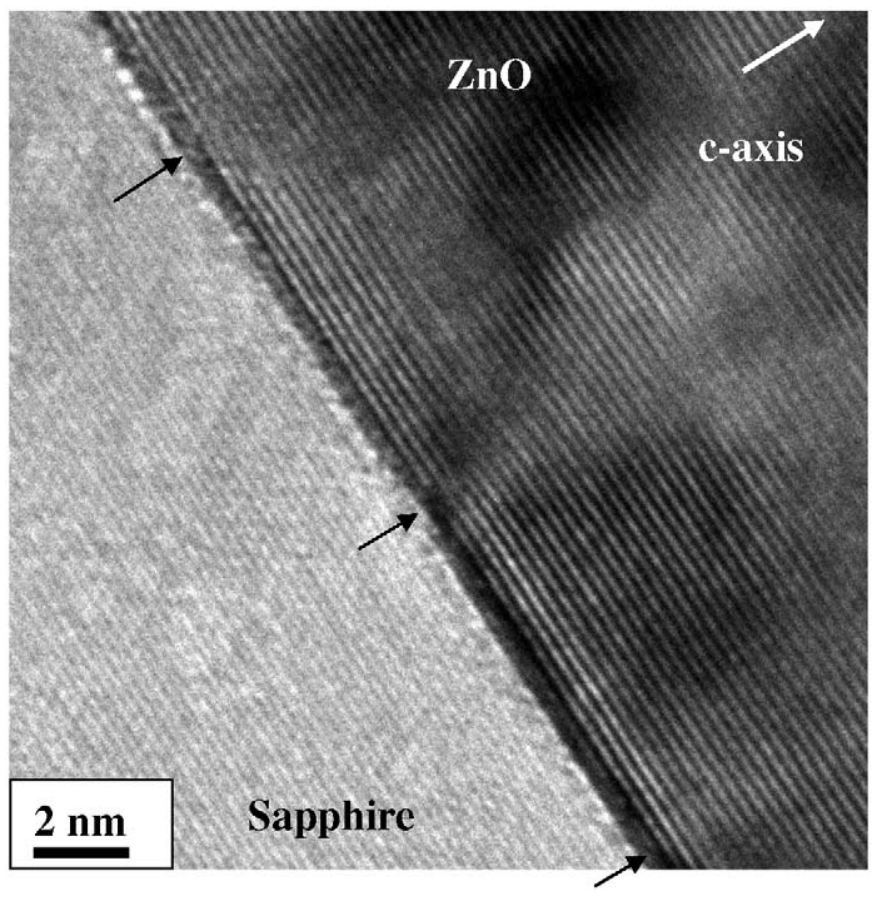

Fig. 7. Another TEM image showing the interface between sapphire substrate and $\mathrm{ZnO}$ of sample $\mathrm{A}$. The marked points indicate the starting points of three threading dislocations.

lattice mismatch between $\mathrm{ZnO}$ and sapphire from $31.5 \%$ to $18.3 \%$ [15]. Although it is difficult to calibrate the correspondence between the $18.3 \%$ lattice mismatch and the observed 8-nm separation of threading dislocation, this distance can be interpreted as the extent of strain the system can stand before the bond breakage and the

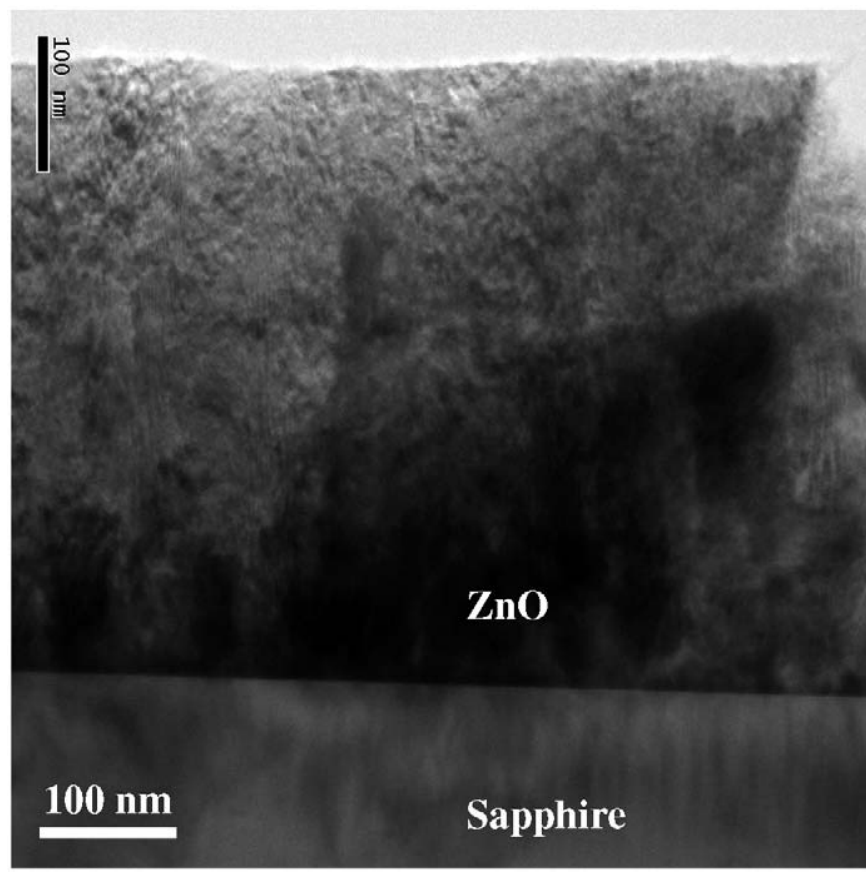

Fig. 8. A large-scale TEM image of sample B.

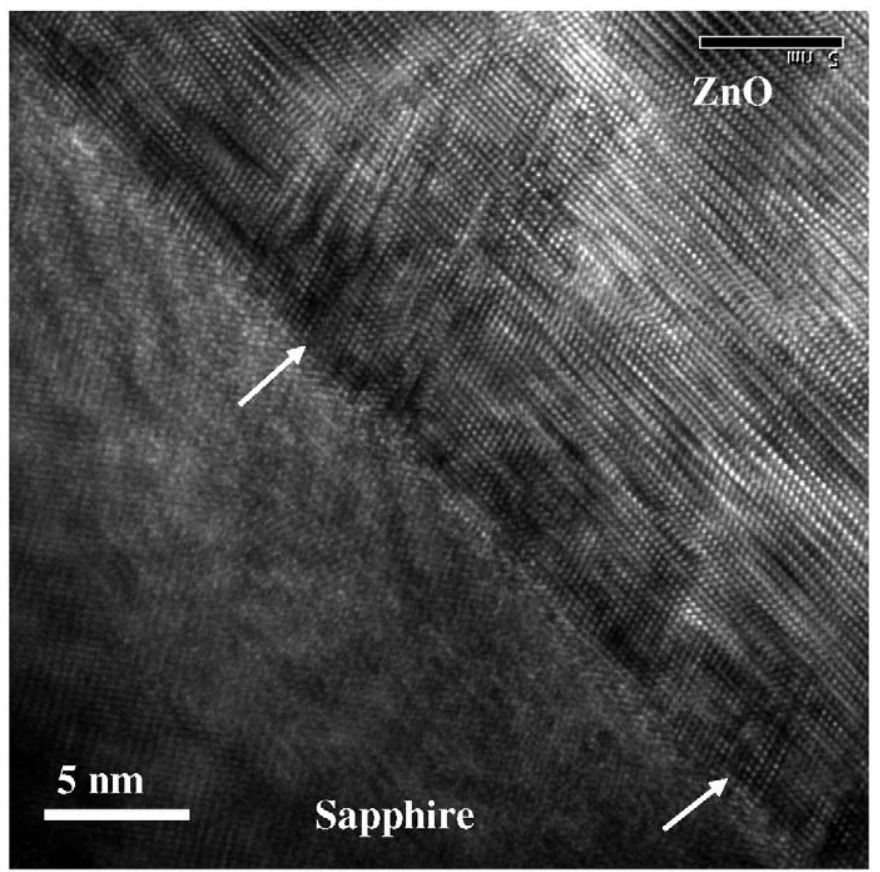

Fig. 9. A TEM image showing the interface between the sapphire substrate and $\mathrm{ZnO}$ of sample $\mathrm{B}$. The stacking faults in $\mathrm{ZnO}$ indicate the strong strain distribution near the interface.

formation of misfit dislocations. Without the $30^{\circ}$ basalplane twist, the dislocation density may become higher.

Fig. 8 shows a large-scale TEM image of sample B. Here, a continuous layer of $\mathrm{ZnO}$ of about $500 \mathrm{~nm}$ in thickness can be seen. This continuous structure is consistent with the surface morphology in Fig. 2 and is quite different from that of sample A. Fig. 9 shows the atomic-scale image at the interface between the sapphire substrate and $\mathrm{ZnO}$ of 
sample B. Here, the atomic dot images for both sapphire and $\mathrm{ZnO}$ can be seen, confirming that the crystal orientation of $\mathrm{ZnO}$ is not twisted with respect to sapphire. Basically, the interface is clear although not as sharp as that in sample A. However, plenty of stacking faults can be seen in $\mathrm{ZnO}$ near the interface, indicating that strong strains are distributed in this region. It has been discussed that a twist of crystal orientation in the basal plane of the hexagonal structure can relax the strain energy [18]. In the case of low-temperature growth, the incorporated atoms do not have sufficient thermal energy for forming the twisted structure such that the built strains are stronger in sample B. In Fig. 9, two regions of line structures oriented about $75^{\circ}$ with respect to the interface can also be seen. Such line structures represent the misfit defects for relaxing the lattice mismatch-built strains.

Fig. 10 shows a large-scale TEM image of sample C. Near the top, domain structures similar to those of sample A can be observed. However, the scale size along the interface dimension is larger, on the order of $150 \mathrm{~nm}$. This observation is again consistent with the surface morphology, as shown in Fig. 3. Also, from Fig. 10 one can see that the domain structures in sample $\mathrm{C}$ are actually connected near the interface, similar to the case of sample B. This observation is reasonable because in the first $5 \mathrm{~min}$ of growth for sample C, the growth temperature was $200^{\circ} \mathrm{C}$, the same as that for the whole growth process of sample B. Fig. 11 shows an image near the interface of sample $C$. Here, one can see that the $\mathrm{ZnO}$ crystalline quality near the interface is quite poor, similar to the case of sample B. Line structures like those in sample B can also be observed. Here, again the observable atomic dot matrices in both

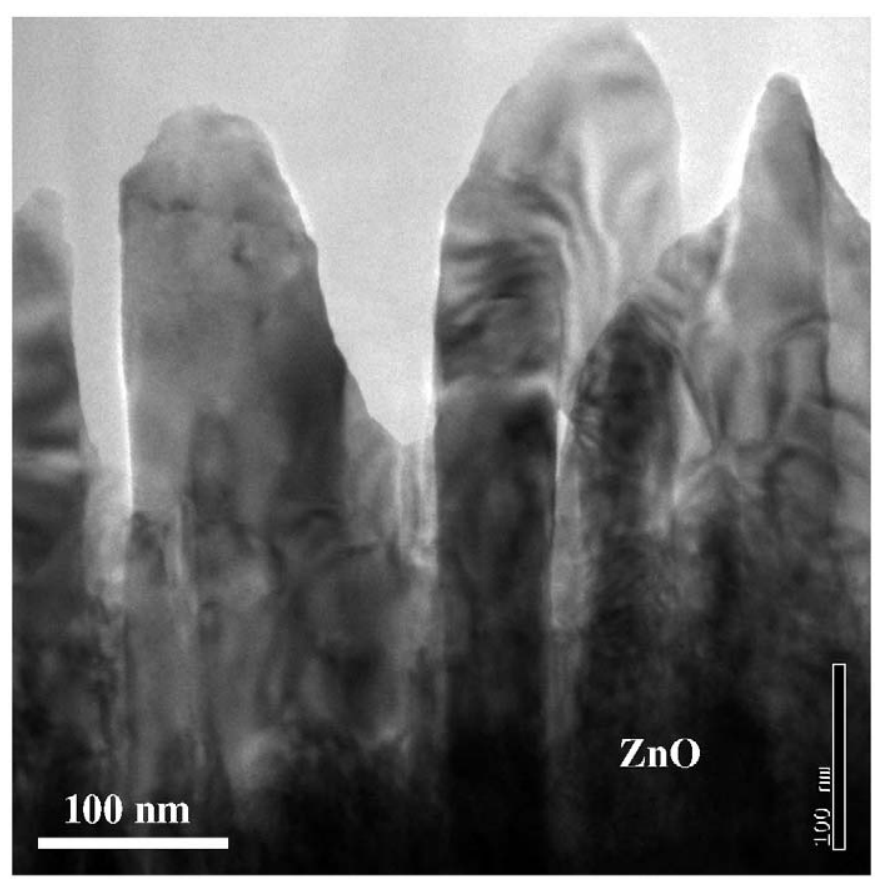

Fig. 10. A large-scale TEM image of sample $\mathrm{C}$ showing the domain structures. The domain width is around $150 \mathrm{~nm}$.

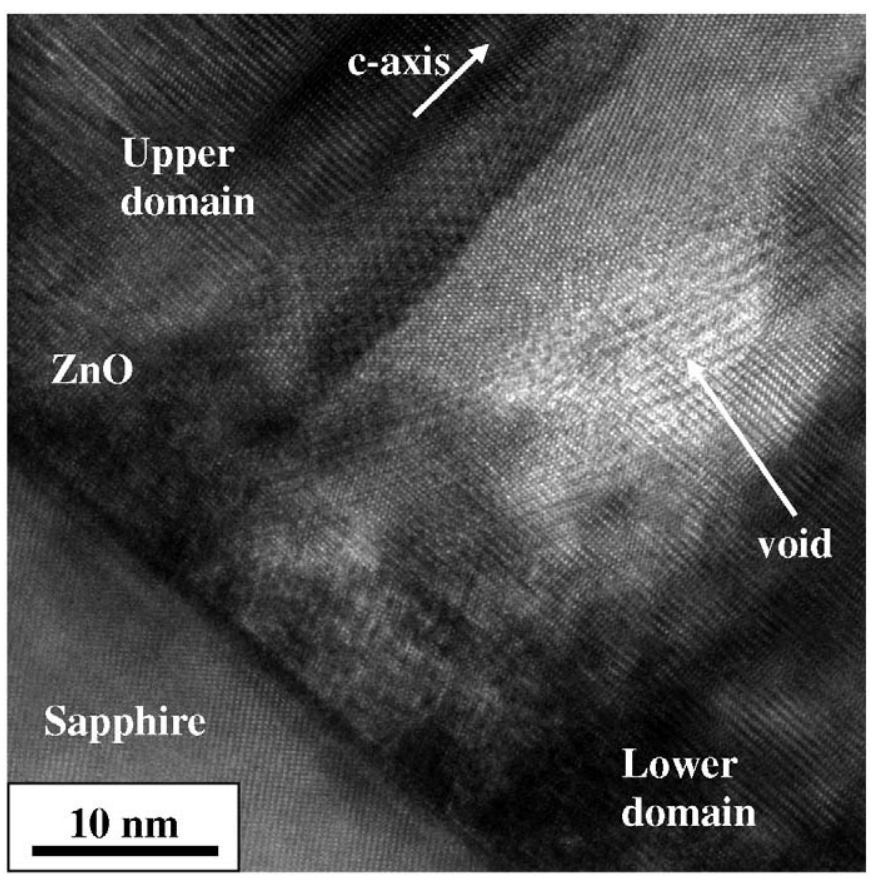

Fig. 11. A TEM image showing the interface between the sapphire substrate and $\mathrm{ZnO}$ of sample $\mathrm{C}$.

sapphire and $\mathrm{ZnO}$ confirm that the $\mathrm{ZnO}$ crystalline is not twisted in the basal plane with respect to sapphire in sample C.

Note that although a void-like structure exists between the upper and lower domains in Fig. 11, the atomic arrangement essentially connects the two domains near the interface. Because the growth condition of this region is the same as that of the whole growth process of sample B, the observed void-like structure can be used for explaining the blurred domain structures of sample B, as shown in Fig. 2 . Void-like structures could be generated during the lowtemperature growth. Such a void-like structure near the interface may become the seed of the domain gap between two evolving domains when the growth temperature is elevated to $450^{\circ} \mathrm{C}$. Here, one can see the sharp boundary between the upper domain and the gap. However, the smooth transition between the lower domain and the gap can be observed. It is difficult to clearly determine the boundary of the lower domain. This image may demonstrate a spiral structure, in which the crystalline portion of the lower domain extends gradually away from the HRTEM focal point and then returns to the focal point to show the upper domain. The gap in Fig. 11 may correspond to the crystalline portion away from the focal point. In sample $\mathrm{C}$, the atomic-scale image of the $\mathrm{ZnO}$ layer near the top surface (not shown in this paper) shows that except a few lines of stacking faults, the $\mathrm{ZnO}$ crystalline structure is quite good in the high-temperature growth portion.

The domain structures formed with the high-temperature growth are attributed to the higher growth speed of $\mathrm{ZnO}$ along the $c$-axis. It is more likely to implement the 
2-D growth mode at the low temperature. In this situation, however, void-like structures may exist and the crystalline quality is relatively poorer.

\section{Basic optical properties}

In Figs. 12 and 13, we show the temperature-dependent photoluminescence (PL) spectra of samples A and C, respectively. The PL intensity of sample B is too weak to be measured with our equipment indicating the poor optical quality of this sample that is consistent with the results of material analysis. In Fig. 12 for sample A, at $10 \mathrm{~K}$ the peak near $3.36 \mathrm{eV}$ corresponds to $\mathrm{D}^{0} \mathrm{X}$. That near $3.37 \mathrm{eV}$ beyond $40 \mathrm{~K}$ corresponds to FX. Also, the evolving peak

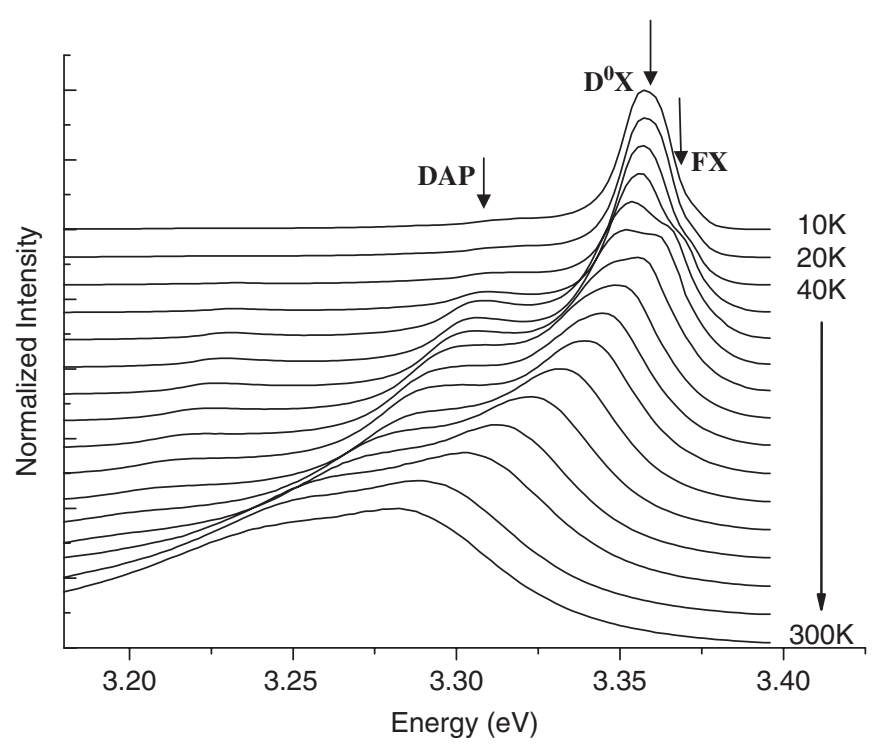

Fig. 12. PL spectra of sample A at various temperatures.

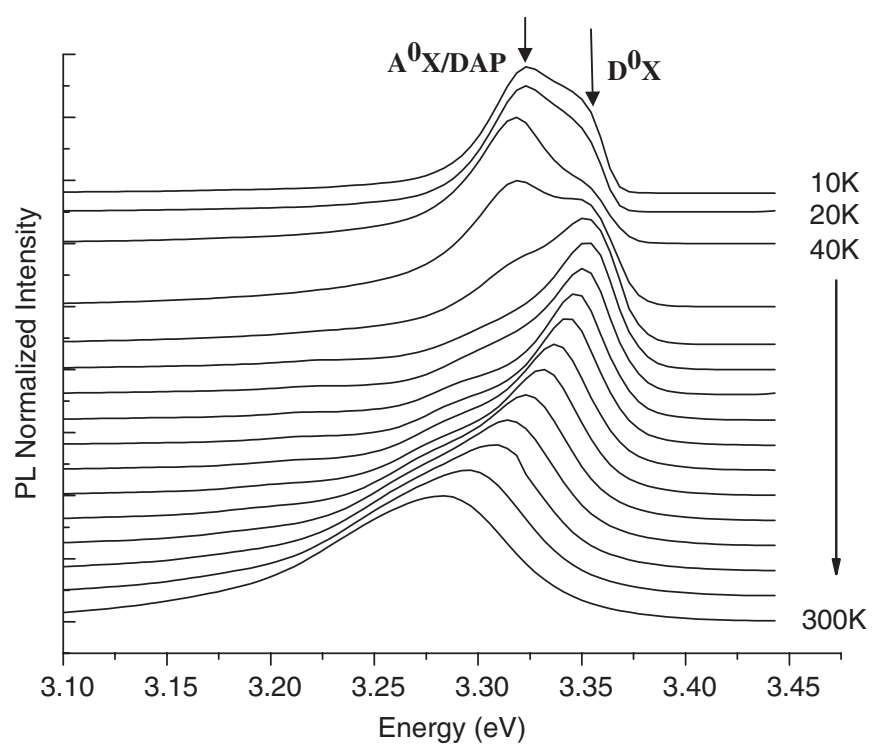

Fig. 13. PL spectra of sample $\mathrm{C}$ at various temperatures. around $3.3 \mathrm{eV}$ beyond $60 \mathrm{~K}$ is due to the contributions of DAP and one-LO-phonon-assisted FX emission. Below $40 \mathrm{~K}$, excitons are mainly trapped by neutral donors. Because of the thermal energy, excitons are thermalized into free states to form the FX peak beyond $40 \mathrm{~K}$. This peak becomes dominating and starts to red shift due to the thermal effect beyond $80 \mathrm{~K}$. In the thermal effect, lattice vibration weakens the bond strength and reduces the band gap of the semiconductor. Beyond $140 \mathrm{~K}$, the thermal energy is larger than the binding energy of a neutral donor and hence FX and $\mathrm{D}^{0} \mathrm{X}$ become mixed. When the temperature approaches the room temperature, the complex of $\mathrm{FX}$ and $\mathrm{D}^{0} \mathrm{X}$ mix with the contributions of DAP and one-LO-phonon-assisted FX emission. In this situation, DAP may be thermalized into the state of $\mathrm{eA}^{0}$. The PL behaviors in Fig. 12 were commonly observed in highquality $\mathrm{ZnO}$ samples [19].

The PL behaviors in Fig. 13 for sample $\mathrm{C}$ are rather different. At $10 \mathrm{~K}$, besides the minor peak near $3.36 \mathrm{eV}$ of $\mathrm{D}^{0} \mathrm{X}$, there is a broad major peak around $3.325 \mathrm{eV}$. This peak may cover the possible contribution of DAP near $3.3 \mathrm{eV}$ at $10 \mathrm{~K}$. It can also be attributed to the increase of the $\mathrm{A}^{0} \mathrm{X}$ density [20]. The effective deep acceptor defects are mainly due to the existence of $\mathrm{O}$ interstitials and $\mathrm{Zn}$ vacancies in the sample. It is speculated that the lowtemperature (low-quality) growth in the initial stage of sample $\mathrm{C}$ led to a higher acceptor density in the shallow layer, which is the major sample portion of the PL measurement, although the higher temperature was used in the later-stage growth. At low temperatures, the excitons are trapped by the deep-level neutral acceptors. Beyond $80 \mathrm{~K}$, they are mainly thermalized into $\mathrm{D}^{0} \mathrm{X}$ and then FX. Eventually, FX emission dominates at room temperature. The existence of the acceptor feature indicates the major difference in material structure between samples A and C. Although it requires further investigation, based on the comparison between samples $\mathrm{A}$ and $\mathrm{C}$, the low-temperature initial-growth stage seems to increase the acceptor density.

In Fig. 14, we show the integrated PL intensities as functions of temperature for samples A and C. The decay rate of the integrated PL intensity is usually used to describe the density of non-radiative recombination center in a sample. The steeper decay with increasing temperature of sample $\mathrm{C}$ implies that the density of non-radiative recombination centers in this sample is higher than that of sample A. It is noted that the thermal quenching process of the integrated PL intensity in sample A shows a turning point at $80 \mathrm{~K}$, beyond which the quenching rate is reduced. From Fig. 14, one can see the coincidence with the temperature of the emergence of FX. Also, a similar turning point exists at $120 \mathrm{~K}$ for sample C. From Fig. 13, one can see that this temperature corresponds to the point that the $\mathrm{A}^{0} \mathrm{X}$ emission becomes less important and FX begins to dominate. Based on such an observation, one can conclude that the trapping of excitons by neutral donors or acceptors may create a channel of non-radiative 


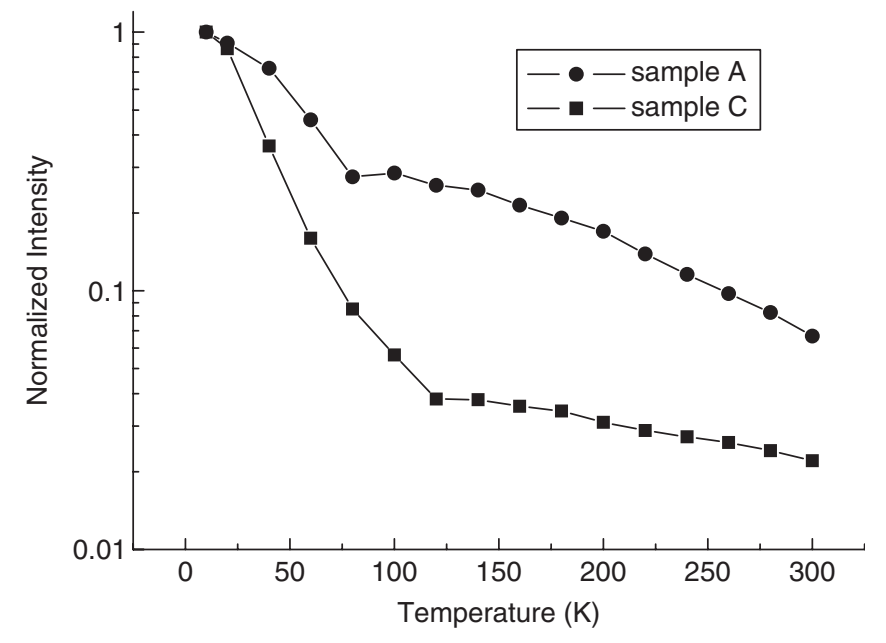

Fig. 14. Integrated PL intensities as functions of temperature of samples $\mathrm{A}$ and $\mathrm{C}$.

recombination. Excitons may relax from the defect levels through phonon generation. As temperature increases to provide thermal energy for ionizing excitons from the defect trapping to become FXs, the thermal quenching rate is reduced. Therefore, beyond $80 \mathrm{~K}$ for sample $\mathrm{A}$ and beyond $120 \mathrm{~K}$ for sample $\mathrm{B}$, the decay slopes of the integrated PL intensities of samples $\mathrm{A}$ and $\mathrm{C}$ become shallower.

\section{Conclusions}

In summary, we have compared the nano-structures of three $\mathrm{ZnO}$ thin films grown on sapphire under different growth temperature conditions. Although disconnected domain structures were observed in the samples of hightemperature growth, their crystal quality was generally better than the one grown at the low temperature. Lattice misfits and threading dislocations were observed within a domain with the separation of about $8 \mathrm{~nm}$. The sample grown at the low temperature showed a continuous structure through the $\mathrm{ZnO}$ layer although void-like structures might exist inside. However, its crystal quality was relatively poorer. Of the two samples with hightemperature growth, the one with initial low-temperature growth had a larger domain structure and relatively lower crystal quality. In particular, strong strains existed near the interface of this sample. The samples of high-temperature growth generally had higher photon emission efficiencies. From the observation of the temperature-dependent integrated photoluminescence intensities of the hightemperature-growth samples, one could conclude that the exciton trapping by either intrinsic donors or acceptors leads to a higher thermal quenching rate in comparison with free excitons.

\section{Acknowledgement}

This research was supported by National Science Council, The Republic of China, under the grant of NSC 93-2210-M-002-006 and NSC 94-2215-E-002-015, and by US Air Force under the contracts AOARD-04-4026 and AOARD-05-4085.

\section{References}

[1] X.W. Sun, S.F. Yu, C.X. Xu, C. Yuen, B.J. Chen, S. Li, Jpn. J. Appl. Phys. 42 (2003) 229.

[2] W.I. Park, Y.H. Jun, S.W. Jung, G. Yi, Appl. Phys. Lett. 82 (2003) 964.

[3] H.T. Ng, J. Li, M.K. Smith, P. Nguyen, A. Cassell, J. Han, M. Meyyappan, Science 300 (2003) 1249.

[4] Y. Chen, D. Bagnall, T. Yao, Mater. Sci. Eng. B 77 (2000) 190.

[5] D.C. Look, D.C. Reynolds, C.W. Litton, R.L. Jones, D.B. Eason, G. Cantwell, Appl. Phys. Lett. 81 (2002) 1830.

[6] K. Haga, T. Suzuki, Y. Kashiwaba, H. Watanabe, B.P. Zhang, Y. Segawa, Thin Solid Films 433 (2003) 131.

[7] T. Gruber, C. Kirchner, K. Thonke, R. Sauer, A. Waag, Phys. Stat. Sol. (a) 192 (2002) 166.

[8] S.F. Chichibu, T. Yoshida, T. Onuma, H. Nakanishi, J. Appl. Phys. 91 (2002) 874.

[9] B.P. Zhang, N.T. Binh, K. Wakatsuki, C.Y. Liu, Y. Segawa, N. Usami, Appl. Phys. Lett. 86 (2005) 032105.

[10] B. Guo, Z.R. Qiu, K.S. Wong, Appl. Phys. Lett. 82 (2003) 2290.

[11] Q.X. Zhao, M. Willander, R.E. Morjan, Q.H. Hu, E.E.B. Campbell, Appl. Phys. Lett. 83 (2003) 165.

[12] B.P. Zhang, N.T. Binh, Y. Segawa, K. Wakatsuki, N. Usami, Appl. Phys. Lett. 83 (2003) 1635.

[13] K.I. Qgata, T. Kawanishi, K. Maejima, K. Sakura, S. Fujita, Jpn. J. Appl. Phys. 40 (2001) 657.

[14] Th. Gruber, C. Kirchner, K. Thonke, R. Sauer, A. Waag, Phys. Stat. Sol. (a) 192 (2002) 166.

[15] B.P. Zhang, K. Wakatsuki, N.T. Binh, N. Usami, Y. Segawa, Thin Solid Films 449 (2004) 12.

[16] S. Muthukumar, H. Sheng, J. Zhong, Z. Zhang, N.W. Emanetoglu, Y. Lu, IEEE Trans. Nanotechnol. 2 (2003) 50.

[17] B.P. Zhang, N.T. Binh, K. Wakatsuki, Y. Segawa, Y. Yamada, N. Usami, M. Kawasaki, H. Koinuma, J. Phys. Chem. B 108 (2004) 10899.

[18] B.P. Zhang, N.T. Binh, K. Wakatsuki, N. Usami, Y. Segawa, Appl. Phys. A 78 (2004) 25.

[19] O. Pagni, G.R. James, A.W.R. Leitch, Phys. Stat. Sol. (c) 1 (2004) 864.

[20] H. Kato, M. Sano, K. Miyamoto, T. Yao, Jpn. J. Appl. Phys. 42 (2003) 2241. 